\title{
A Six-Year Review of Head and Neck Cancers at the Komfo Anokye Teaching Hospital, Kumasi, Ghana
}

\author{
Rita Larsen-Reindorf ${ }^{*}$, Osei Owusu-Afriyie² ${ }^{2}$, Alexander Oti Acheampong ${ }^{3}$, Isaac Boakye ${ }^{4}$, \\ Baffour Awuah ${ }^{5}$ \\ ${ }^{1}$ Department of ENT, Komfo Anokye Teaching Hospital, Kumasi, Ghana \\ ${ }^{2}$ Department of Pathology, Komfo Anokye Teaching Hospital, Kumasi, Ghana \\ ${ }^{3}$ Department of Oral and Maxillofacial Unit, Komfo Anokye Teaching Hospital, Kumasi, Ghana \\ ${ }^{4}$ Research \& Development Unit, Komfo Anokye Teaching Hospital, Kumasi, Ghana \\ ${ }^{5}$ Directorate of Oncology, Komfo Anokye Teaching Hospital, Kumasi, Ghana \\ Email: * ritaasamoahowusu@yahoo.com
}

Received 17 July 2014; revised 10 August 2014; accepted 2 September 2014

Copyright (C) 2014 by authors and Scientific Research Publishing Inc.

This work is licensed under the Creative Commons Attribution International License (CC BY).

http://creativecommons.org/licenses/by/4.0/

(c) (i) Open Access

\begin{abstract}
Background: In Ghana, information on the prevalence and pattern of Head and Neck Cancers (HNCA) is scarce. There are few publications based on specific sub-sites of the head and neck, however, literature on the prevalence and pattern of HNCA in general is lacking. The present study aimed to describe the pattern of HNCA among patients seen at the multidisciplinary HNCA clinic of Komfo Anokye Teaching Hospital. Methods: This is a retrospective review of all consecutive patient records seen at the multidisciplinary clinic from 2004 to 2009. Results: There were 149 males and 103 females giving a male to female ratio of 1.45:1. The age range was 2 - 95 years with a mean of 48.1 years. The commonest type of HNCA in this review is cancers of the oral cavity (29.4\%), followed by accessory sinuses (13.9\%) and larynx (13.5\%). Nasopharyngeal cancer affected young people, with $34.5 \%$ of affected patients aged between 10 and 19 years. The commonest histopathological type was squamous cell carcinoma $(49.6 \%)$. Majority $(47.6 \%)$ of patients presented at stage IV. Conclusion: The commonest HNCA is oral cancer. Majority of patients with HNCA are presenting late calling for public health education to raise awareness and promote early detection.
\end{abstract}

\section{Keywords}

Head and Neck Cancer, Oral Cavity, Squamous Cell Carcinoma

\footnotetext{
*Corresponding author.
}

How to cite this paper: Larsen-Reindorf, R., Owusu-Afriyie, O., Acheampong, A.O., Boakye, I. and Awuah, B. (2014) A Six-Year Review of Head and Neck Cancers at the Komfo Anokye Teaching Hospital, Kumasi, Ghana. International Journal of Otolaryngology and Head \& Neck Surgery, 3, 271-278. http://dx.doi.org/10.4236/ijohns.2014.35050 


\section{Introduction}

The term Head and Neck Cancers (HNCA) refers to a group of biologically similar cancers originating from the upper aerodigestive tract including the oral cavity, nasal cavity, paranasal sinuses, pharynx and larynx [1].

Tobacco and alcohol play an important role in the aetio-pathogenesis of HNCA [2] and according to Manure and Forasteire, tobacco consumption associated with alcohol consumption increases the head and neck cancer risk 40-fold [3]. Over the past decade we have also become aware that a significant proportion of head and neck cancers result from infection by some human papilloma virus types [4].

Head and neck cancers constitute one of the commonest cancers accounting for $5 \%$ - 50\% of all cancers globally [5]. Head and neck cancers make up 5\% - 8\% of total body cancers in Europe and America [6]-[8] whilst in India it forms about $30 \%$ of all cancers [9]. A study of head and neck tumours at a tertiary centre in Nigeria [10] showed $55.5 \%$ of the tumours to be malignant. In Ghana, there are few publications based on specific sub-sites of the head and neck [11], however, literature on the prevalence and pattern of head and neck cancers in general is lacking. A publication on head and neck tumours in Ghanaian children by Abdulai et al. concluded that malignancies of the head and neck are not rare in Ghana [12].

The management of patients with HNCA is complex. Vital functions such as breathing, speech and swallowing can be affected by both the cancer and its treatment. It is for these, among other reasons, that patients afflicted with HNCA need access to a full range of specialists and support services with the expertise in the management of their condition for optimal treatment and follow-up.

This background led to the establishment in 2004 of a multidisciplinary team at the Komfo Anokye Teaching hospital (KATH) with the aim of working together to create a comprehensive treatment plan for our head and neck cancer patients to achieve the best possible outcome. The HNCA clinic in the first three years runs fortnightly but subsequently has run weekly. The clinic is a multi-disciplinary specialist clinic comprising of ear, nose and throat head and neck surgeons, radiation oncologists, oral maxillofacial surgeons, ophthalmologists, radiologists, pathologists, social workers, pharmacists and specialist nurses. Eight years following the establishment of the HNCA multidisciplinary clinic, it was deemed necessary to review the pattern of head and neck cancer cases seen at this centre since the spectrum of head and neck cancers vary from place to place [13]-[16].

The present review therefore sought to retrospectively examine HNCA cases seen at this multidisciplinary clinic from 2004 to 2009. This was to serve as a baseline data for further detailed study, create awareness of HNCA as well as determine the pattern of head and neck cancer cases seen at the Komfo Anokye Teaching Hospital.

\section{Materials and Methods}

The Komfo Anokye Teaching Hospital (KATH) has a 1200-bed capacity and is a tertiary referral hospital for the northern and middle belts of Ghana and this area constitutes two-thirds of the land size of Ghana. KATH is located in Kumasi, the Ashanti regional capital of Ghana with a total population of 2.4 million.

All patients referred to Komfo Anokye Teaching Hospital or diagnosed by the multi-disciplinary team of doctors were presented at the weekly meeting of the head and neck cancer clinic. Each case was discussed and a management plan decided upon.

This is a retrospective review of all consecutive patient records seen at the multidisciplinary clinic from 2004 to 2009. A special data collection form was created to gather the following information from patients' records: Socio-demographic, clinical, and pathological data. Information was entered into Microsoft ${ }^{\circledR}$ excel for editing and cleaning.

In this review, malignancies of the head and neck region were classified according to the current World Health Organization's International Classification of Disease coding system.

Data was then transferred to Stata/SE 11.1 statistical software for analysis. Basic descriptive analysis was conducted for quantitative continuous variables whereas categorical variables were presented with their proportions. Regarding measures of central tendency, means were reported for quantitative continuous variables that were normally distributed and median for quantitative continuous variables that were not normally distributed; a measure of dispersion using range and standard deviation were also used.

\section{Results}

During the six-year period, 311 head and neck cancer cases were recorded out of a total of 3162 cases of total 
body malignancies recorded at the centre. Head and neck cancers thus accounted for $9.8 \%$ of all malignancies seen during the study period. Out of the 311 recorded cases, 252 of them constituting $81 \%$ had documentary evidence of a confirmed histological diagnosis. Hence, subsequent data analysis was based on the 252 histologically confirmed cases. There were 149 males and 103 females giving a male to female ratio of 1.45:1. The mean age was 48 years with a standard deviation of 19 years (range: 2 to 95 years). The peak occurrence was between 50 and 59 years comprising $21.4 \%$. Ten percent (10\%) of the patients were below 20 years of age (Table 1 ).

The commonest HNCA was oral cavity cancer accounting for $29.4 \%$ followed by cancer of the accessory sinuses (13.9\%) and laryngeal cancer (13.5\%). Cancer of the hypopharynx was the least common comprising $0.8 \%$ (Table 1 ).

With regards to the pattern of head and neck cancers based on gender it was observed that cancer of the oral cavity was the commonest head and neck cancer in both males and females. However in the males, laryngeal cancer was the second commonest accounting for $20.8 \%$ followed by cancer of the accessory sinuses (12.8\%) whereas in the females cancer of the accessory sinuses (15.5\%) and thyroid gland (15.5\%) were the second commonest (Table 2).

The head and neck cancer clinic in Kumasi received cases from all the 10 regions of Ghana as well as from neighbouring Burkina Faso and La Cote D'Ivoire. The majority of cases (73.8\%) were from the middle belt of Ghana made up of Ashanti region (63.9\%) and Brong Ahafo (10.1\%) as shown in Table 3.

Of the cases seen, $92.7 \%$ were referred from state or public hospitals, and $1.7 \%$ each being referrals from hospitals outside Ghana and private hospitals (Table 3).

\begin{tabular}{|c|c|c|}
\hline & $(\mathrm{n}=252)$ & n (\%) \\
\hline \multirow{6}{*}{ Year } & 2004 & $39(15.5)$ \\
\hline & 2005 & $38(15.1)$ \\
\hline & 2006 & $42(16.7)$ \\
\hline & 2007 & $32(12.7)$ \\
\hline & 2008 & $44(17.5)$ \\
\hline & 2009 & $57(22.6)$ \\
\hline \multirow{9}{*}{ Age group (years) } & 0 - 9 years & $8(3.2)$ \\
\hline & $10-19$ years & $17(6.8)$ \\
\hline & 20 - 29 years & $22(8.7)$ \\
\hline & 30 - 39 years & $32(12.7)$ \\
\hline & $40-49$ years & $42(16.7)$ \\
\hline & 50 - 59 years & $54(21.4)$ \\
\hline & 60 - 69 years & $38(15.1)$ \\
\hline & 70 - 79 years & $27(10.7)$ \\
\hline & 80 - 95 years & $12(4.8)$ \\
\hline \multirow{9}{*}{ Primary site } & Accessory sinuses & $35(13.9)$ \\
\hline & Hypopharynx & $2(0.8)$ \\
\hline & Larynx & $34(13.5)$ \\
\hline & Nasal cavity and middle ear & $12(4.8)$ \\
\hline & Nasopharynx & 29 (11.5) \\
\hline & Oral cavity & $74(29.4)$ \\
\hline & Oropharynx & $14(5.6)$ \\
\hline & Salivary gland & $31(12.3)$ \\
\hline & Thyroid gland & $21(8.3)$ \\
\hline
\end{tabular}


Table 2. Table showing gender distribution of primary sites.

\begin{tabular}{cccc}
\hline \multirow{2}{*}{ Primary site } & \multicolumn{2}{c}{ Sex } & \\
\cline { 2 - 3 } & Female, $\mathrm{n}(\%)$ & Male, $\mathrm{n}(\%)$ & Total, $\mathrm{n}(\%)$ \\
\hline Accessory sinuses & $16(15.5)$ & $19(12.8)$ & $35(13.9)$ \\
Hypopharynx & $1(1.0)$ & $1(0.7)$ & $2(0.8)$ \\
Larynx & $3(2.9)$ & $31(20.8)$ & $34(13.5)$ \\
Nasal cavity and middle ear & $7(6.8)$ & $5(3.4)$ & $12(4.8)$ \\
Nasopharynx & $13(12.6)$ & $16(10.7)$ & $29(11.5)$ \\
Oral cavity & $29(28.2)$ & $45(30.2)$ & $74(29.4)$ \\
Oropharynx & $4(3.9)$ & $10(6.7)$ & $14(5.6)$ \\
Salivary gland & $14(13.6)$ & $17(11.4)$ & $31(12.3)$ \\
Thyroid gland & $16(15.5)$ & $5(3.4)$ & $21(8.3)$ \\
Total & $103(100)$ & $149(100)$ & $252(100)$ \\
\hline
\end{tabular}

Table 3. Table showing geographical distribution and source of referral of HNCA.

\begin{tabular}{lcc}
\hline & & $\mathrm{n}(\%)$ \\
\hline & Ashanti & $152(63.9)$ \\
Geographical region $(\mathrm{n}=238)$ & Western & $24(10.1)$ \\
& Central & $15(6.3)$ \\
& Northern & $11(4.6)$ \\
& Eastern & $11(4.6)$ \\
Referral facility $(\mathrm{n}=233)$ & Upper East & $8(3.4)$ \\
& Upper West & $4(1.7)$ \\
& Greater Accra & $4(1.7)$ \\
& Volta & $3(1.3)$ \\
& Burkina Faso & $2(0.8)$ \\
& Cote D’voire & $3(1.3)$ \\
State (public) hospital & $1(0.4)$ \\
Mission hospital & $216(92.7)$ \\
\hline
\end{tabular}

Squamous cell carcinoma (SCC) was the commonest histopathological diagnosis, comprising $49.6 \%$. This was followed by undifferentiated nasopharyngeal carcinoma (10.7\%), sarcomas (6.8\%) and adenocarcinoma (6.4\%) (Table 4).

Majority of the cases presented late with almost half (47.6\%) of them presenting at stage IV and $14.7 \%$ of the cases presenting at stage III. Stage I and II cases accounted for $2.0 \%$ and $7.5 \%$ respectively. Unfortunately, in $27.8 \%$ of the cases presented no staging had been assigned except for documentation as being locally advanced (Table 4).

Nasopharyngeal carcinoma was commonest in the second decade of life (34.5\%) while cancer of the accessory sinuses, larynx, oral cavity, oropharynx, salivary gland and thyroid were seen mostly in the fifth, sixth and seventh decades (Table 5). 
Table 4. Table showing histological sub type and stage.

\begin{tabular}{|c|c|c|}
\hline & & n (\%) \\
\hline \multirow{14}{*}{ Histology $(n=252)$} & Squamous cell carcinoma & 125 (49.6) \\
\hline & Undifferentiated nasopharyngeal carcinoma & $27(10.7)$ \\
\hline & Sarcoma & $18(7.2)$ \\
\hline & Adenocarcinoma & $16(6.4)$ \\
\hline & Others & $14(5.6)$ \\
\hline & Mucoepidermoid carcinoma & $12(4.8)$ \\
\hline & Thyroid follicular carcinoma & $9(3.6)$ \\
\hline & Thyroid papillary carcinoma & $7(2.8)$ \\
\hline & Lymphoma & $7(2.8)$ \\
\hline & Carcinoma NOS & $6(2.4)$ \\
\hline & Adenoid cystic carcinoma & $5(2.0)$ \\
\hline & Undifferentiated carcinoma & $4(1.6)$ \\
\hline & Thyroid anaplastic carcinoma & $1(0.4)$ \\
\hline & Neuroendocrine carcinoma & $1(0.4)$ \\
\hline \multirow{6}{*}{ Cancer stage } & I & $5(2.0)$ \\
\hline & II & $19(7.5)$ \\
\hline & III & $37(14.7)$ \\
\hline & IV & $120(47.6)$ \\
\hline & Recurrent & $1(0.4)$ \\
\hline & Unknown & $70(27.8)$ \\
\hline
\end{tabular}

Table 5. Table showing age and primary site distribution of HNCA.

\begin{tabular}{|c|c|c|c|c|c|c|c|c|c|c|}
\hline $\begin{array}{l}\text { Age group } \\
\text { (Years) }\end{array}$ & $\begin{array}{c}\text { Accessory } \\
\text { sinuses, n (\%) }\end{array}$ & $\begin{array}{l}\text { Hypo-pharynx, } \\
\text { n (\%) }\end{array}$ & $\begin{array}{l}\text { Larynx, } \\
\text { n (\%) }\end{array}$ & $\begin{array}{l}\text { Nasal } \\
\text { cavity, n } \\
\text { (\%) }\end{array}$ & $\begin{array}{c}\text { Naso-pharynx, } \\
\text { n (\%) }\end{array}$ & $\begin{array}{l}\text { Oral } \\
\text { cavity, } \\
\text { n (\%) }\end{array}$ & Oro-pharynx & $\begin{array}{l}\text { Salivary } \\
\text { gland }\end{array}$ & $\begin{array}{l}\text { Thyroid } \\
\text { gland }\end{array}$ & Total \\
\hline $0-9$ & 1 & 0 & 0 & 0 & 1 & 4 & 0 & 2 & 0 & 8 \\
\hline $10-19$ & 2 & 0 & 0 & 0 & 10 & 3 & 0 & 2 & 0 & 17 \\
\hline $20-29$ & 5 & 0 & 3 & 1 & 4 & 4 & 0 & 3 & 2 & 22 \\
\hline $30-39$ & 3 & 0 & 2 & 1 & 4 & 10 & 1 & 6 & 5 & 32 \\
\hline $40-49$ & 7 & 0 & 1 & 3 & 4 & 10 & 5 & 6 & 6 & 42 \\
\hline $50-59$ & 6 & 1 & 12 & 2 & 1 & 19 & 3 & 5 & 5 & 54 \\
\hline $60-69$ & 5 & 1 & 11 & 3 & 3 & 9 & 0 & 4 & 2 & 38 \\
\hline $70-79$ & 5 & 0 & 4 & 1 & 0 & 11 & 4 & 1 & 1 & 27 \\
\hline $80-95$ & 1 & 0 & 1 & 1 & 2 & 4 & 1 & 2 & 0 & 12 \\
\hline Total & 35 & 2 & 34 & 12 & 29 & 74 & 14 & 31 & 21 & 252 \\
\hline
\end{tabular}

\section{Discussion}

This review, to the best of our knowledge, is the first to give fairly good data on HNCA in Ghana.

In the early stages of the clinic, late histopathological reporting by the sole pathologist in the hospital at the time and subsequent late archiving in the patients' records was incomplete. This to a large extent explains the lack of documentary evidence of a confirmed histological diagnosis in $19 \%$ of the patients and hence their sub- 
sequent exclusion from further analysis.

This review showed a male preponderance with a male:female ratio of 1.45:1. This falls within the range found by Da Lilly-Tariah et al. which gave a male:female ratio range from 1.1 to 2.3:1 [17]. A lot of studies on head and neck cancers also show a male preponderance [18] [19].

The mean age in this review was 48 years, similar to Adeyemi's study with a mean age of 44 years [10]. Da Lilly-Tariah et al.'s study found that the age distribution of head and neck cancer patients ranged from 9 months to 80 years with a peak between the $3^{\text {rd }}$ and $6^{\text {th }}$ decade of life [17]. In this study the age range was from 2 to 95 years and the peak incidence was in the $6^{\text {th }}$ decade of life. Ten percent $(10 \%)$ of patients in this study were below 20 years of age whilst Adeyemi's study reported that 2.4\% of head and neck cancers occurred in children [10].

Oral cavity malignancies were the commonest in this review comprising $29.4 \%$ (Table 1 ). This is similar to findings by Abdul-Hamid in Yemen where oral cavity malignancy was most common with a prevalence of $31.7 \%$ [20]. Otoh also recorded oral malignancy as being the commonest head and neck malignancy in North Eastern Nigeria with $15.1 \%$ [14]. Similarly, a recent study on the anatomical distribution of head and neck malignant tumours in a Nigerian Teaching hospital, found the oral cavity to be the most common site for head and neck malignancies with a prevalence of 36.8\% [15].

However, in a study by Da Lilly-Tariah et al. which reported on the overall pattern of head and neck malignancy from different regions of Nigeria the nasopharynx was cited as the commonest site, sino-nasal cancers second and cancers of the larynx third [17].

The Head and neck cancer clinic in Kumasi received cases from all the 10 regions of Ghana as well as from neighbouring Burkina Faso and La Cote D'Ivoire. The extensive coverage area of his clinic could be attributed to its strategic location in the middle belt of Ghana since there are only three radiotherapy centres in the country with two of them situated in the capital city of Accra in the South. Even though the majority of cases were designated to be coming from the Ashanti region this could be erroneous (Table 3). With the hospital located in Ashanti region people coming from other parts of the country usually put up with friends and family living close to the hospital and give their addresses as such.

The commonest histopathological tumour type found in this review was squamous cell carcinoma (Table 4) as found by Da Lilly-Tariah and several other studies [10] [17]. However, the percentage (49.6\%) is lower in this study, as compared to $70.5 \%$ found by Abdul-Hamid et al. [20] and $72.09 \%$ by Altumbabic [21]. A larger study may be needed to establish whether the percentage of sqamous cell carcinoma in our region is this low.

In this review almost half of the cases made up of $47.6 \%$ presented with stage IV disease, only $2 \%$ presented with stage I disease (Table 4). This means that majority of the cases presented in advanced stage as was evident in a study by Donkor et al. in Ghana [22]. Da Lilly-Tariah et al. also found that, in our sub-region late presentation is common and treatment is mostly palliative [17]. This calls for further studies to ascertain what may be accounting for the late presentation so that appropriate measures are put in place to halt this trend.

Unfortunately in this review $27.8 \%$ of the cases had not been staged, most had just been documented as being locally advanced (Table 4). This could be due to poor documentation and incomplete radiological investigations required to properly stage the cases. Affordability of these radiological investigations is also a factor since significant numbers of patients affected by HNCA in our setting are financially poor.

In this review, nasopharyngeal malignancy was commonest in the second decade of life (Table 5). In most reports from Nigeria however, the peak age of incidence of nasopharyngeal malignancy was found in the fourth decade of life [15] [16]. There was no clear bimodal distribution of nasopharygeal malignancy in this study which is comparable to that reported by Adham et al. and in his study as well nasopharyngeal malignancy appeared to affect patients at relatively young age [23]. Cancer of the accessory sinuses, larynx, oral cavity, oropharynx, salivary gland and thyroid were seen mostly in the fifth, sixth and seventh decade (Table 5).

\section{Conclusion}

Oral cavity cancers formed the largest group of HNCA. Most of the patients in this review presented late (stage IV). There was no bimodal distribution of nasopharyngeal malignancy. There is the need to undertake public health education to raise awareness in order to promote early detection and reporting to health institutions for further management. There is also the need for urgent education of healthcare providers to improve their documentation and staging of patients. It is time that definite steps are taken to establish a population based cancer 
registry in Ghana. Further studies are definitely needed such as looking at what may be accounting for the late presentation of our patients and what the specific risk factors are in the Ghanaian setting including the role of Human Papilloma virus.

\section{Study Limitation}

The data reflect our specific patient population reporting to the hospital making it an institutional based study and not a population based one.

\section{Acknowledgements}

We thank the hospital authorities for giving us the permission to use data from their archives. We also would like to thank the various staff of the KATH head and neck cancer multidisciplinary team for their cooperation during the study.

\section{References}

[1] Pai, S.I. and Westra, W.H. (2009) Molecular Pathology of Head and Neck Cancer: Implications for Diagnosis, Prognosis, and Treatment. Annual Review of Pathology, 4, 49-70. http://dx.doi.org/10.1146/annurev.pathol.4.110807.092158

[2] Boffetta, P. and Hashibe, M. (2006) Alcohol and Cancer. The Lancet Oncology, 7, 149-156. http://dx.doi.org/10.1016/S1470-2045(06)70577-0

[3] Manur, S. and Forastiere, A.A. (2008) Head and Neck Cancer: Changing Epidemiology, Diagnosis, and Treatment. Mayo Clinic Proceedings, 83, 489-501. http://dx.doi.org/10.4065/83.4.489

[4] Hennessey, P.T., Westra, W.H. and Califana, J.A. (2009) Human Papillomavirus and Head and Neck Squamous Cell Carcinoma: Recent Evidence and Clinical Implications. Journal of Dental Research, 88, 300-306. http://dx.doi.org/10.1177/0022034509333371

[5] Garfinkel, L. (1995) Perspective on Cancer Prevention. A Cancer Journal for Clinicians, 45, 5-9. http://dx.doi.org/10.3322/canjclin.45.1.5

[6] Tobias, J. (1994) Cancer of the Head and Neck. BMJ, 308, 961-966. http://dx.doi.org/10.1136/bmj.308.6934.961

[7] Zagar, G., Smith, J., Norante, J. and McDonald, S. (1993) Tumours of the Head and Neck. In: Rubin, P., Ed., Clinical Oncology: A Multidisciplinary Approach for Physicians and Students, W.B. Saunders, Baltimore, 319-362.

[8] Watkinson, J., Gaze, M. and Wilson, J. (2000) Stella and Maran’s Head and Neck Surgery. 4. Butterworth Heinemann, Oxford, 1-9.

[9] Sanghvi, L.D., Rao, D.N., and Joshi, S. (1989) Epidemiology of Head and Neck Cancer. Seminars in Surgical Oncology, 5, 305-309. http://dx.doi.org/10.1002/ssu.2980050503

[10] Adeyemi, B.F., Adekunle, L.V., Kolude, B.M., Akang, E.E.U. and Lawoyin, J.O. (2008) Head and Neck Cancer-A Clinicopathological Study in a Tertiary Care Center. Journal of the National Medical Association, 100, 690-697.

[11] Kitcher, E., Yarney, J., Gyasi, R. and Cheyuo, C. (2006) Laryngeal Cancer at the Korle-Bu Teaching Hospital Accra Ghana. Ghana Medical Journal, 40, 45-49.

[12] Abdulai, A.E., Nuamah, I.K. and Gyasi, R. (2012) Head and Neck Tumours in Ghanaian Children. A 20 Year Review. International Journal of Oral \& Maxillofacial Surgery, 41, 1378-1382. http://dx.doi.org/10.1016/j.ijom.2012.06.004

[13] Bhatia, P. (1990) Head and Neck Cancer in Plateau State of Nigeria. West African Journal of Medicine, 9, $304-310$.

[14] Otoh, E.C., Johnson, N., Danfillo, I.S., Adeleke, O.A. and Olasoji, H.A. (2004) Primary Head and Neck Cancers in North Eastern Nigeria. West African Journal of Medicine, 23, 305-313.

[15] Amusa, Y.B., Olabanji, J.K., Akinpelu, V.O., Ogundipe, O.V., Olateju, S.O., Agbakwuru, E.A., Ndukwe, N., Fatusi, O.A. and Ojo, O.S. (2004) Pattern of Head and Neck Malignant Tumours in a Nigerian Teaching Hospital—A Ten Year Review. West African Journal of Medicine, 23, 280-285.

[16] Nwawolo, C., Ajekigbe, A., Oyeneyin, J., Nwankwo, K. and Okeowo, P. (2001) Pattern of Head and Neck Cancers among Nigerians in Lagos. West African Journal of Medicine, 20, 111-116.

[17] Da Lilly-Tariah, O.B., Somefun, A.O. and Adeyemo, W.L. (2009) Current Evidence on the Burden of Head and Neck Cancers in Nigeria. Head \& Neck Oncology, 1, 14. http://dx.doi.org/10.1186/1758-3284-1-14

[18] Onyango, J.F. and Macharia, I.M. (2006) Delays in Diagnosis, Referral and Management of Head and Neck Cancer Presenting at Kenyatta National Hospital, Nairobi. East African Medical Journal, 83, 85-91.

http://dx.doi.org/10.4314/eamj.v83i4.9421 
[19] Onyango, J.F., Awange, D.O., Njiru, A. and Macharia, I.M. (2006) Pattern of Occurrence of Head and Neck Cancer Presenting at Kenyatta National Hospital, Nairobi. East African Medical Journal, 83, 288-291. http://dx.doi.org/10.4314/eamj.v83i5.9435

[20] Abdul-Hamid, G., Saeed, N.M., Al-Kahiry, W. and Shukry, S. (2010) Pattern of Head and Neck Cancer in Yemen. Gulf Journal of Oncology, 7, 21-24.

[21] Altumbabić, H., Salkić, A., Ramas, A., Burgić, M., Kasumović, M. and Brkić, F. (2008) Pattern of Head and Neck Malignant Tumours in a Tuzla ENT Clinic-A Five Year Experience. Bosnian Journal of Basic Medical Sciences, 8, 377-380.

[22] Donkor, P. and Boateng, K.A. (2000) Prevalence of Orofacial Squamous Cell Carcinoma Sfeen at Komfo Anokye Teaching Hospital. Ghana Medical Journal, 34, 139-143.

[23] Adham, M., Kurniawan, A.N., Muhtadi, A.I., Roezin, A., Hermani, B., Gondhowiardjo, S., Tan, I.B. and Middeldorp, J.M. (2012) Nasopharyngeal Carcinoma in Indonesia: Epidemiology, Incidence, Signs, and Symptoms at Presentation. Chinese Journal of Cancer, 31, 185-196. 
Scientific Research Publishing (SCIRP) is one of the largest Open Access journal publishers. It is currently publishing more than 200 open access, online, peer-reviewed journals covering a wide range of academic disciplines. SCIRP serves the worldwide academic communities and contributes to the progress and application of science with its publication.

Other selected journals from SCIRP are listed as below. Submit your manuscript to us via either submit@scirp.org or Online Submission Portal.
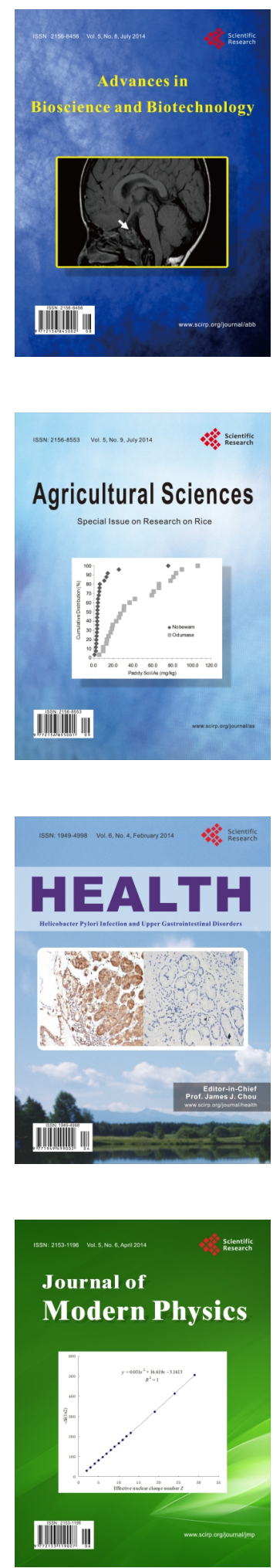
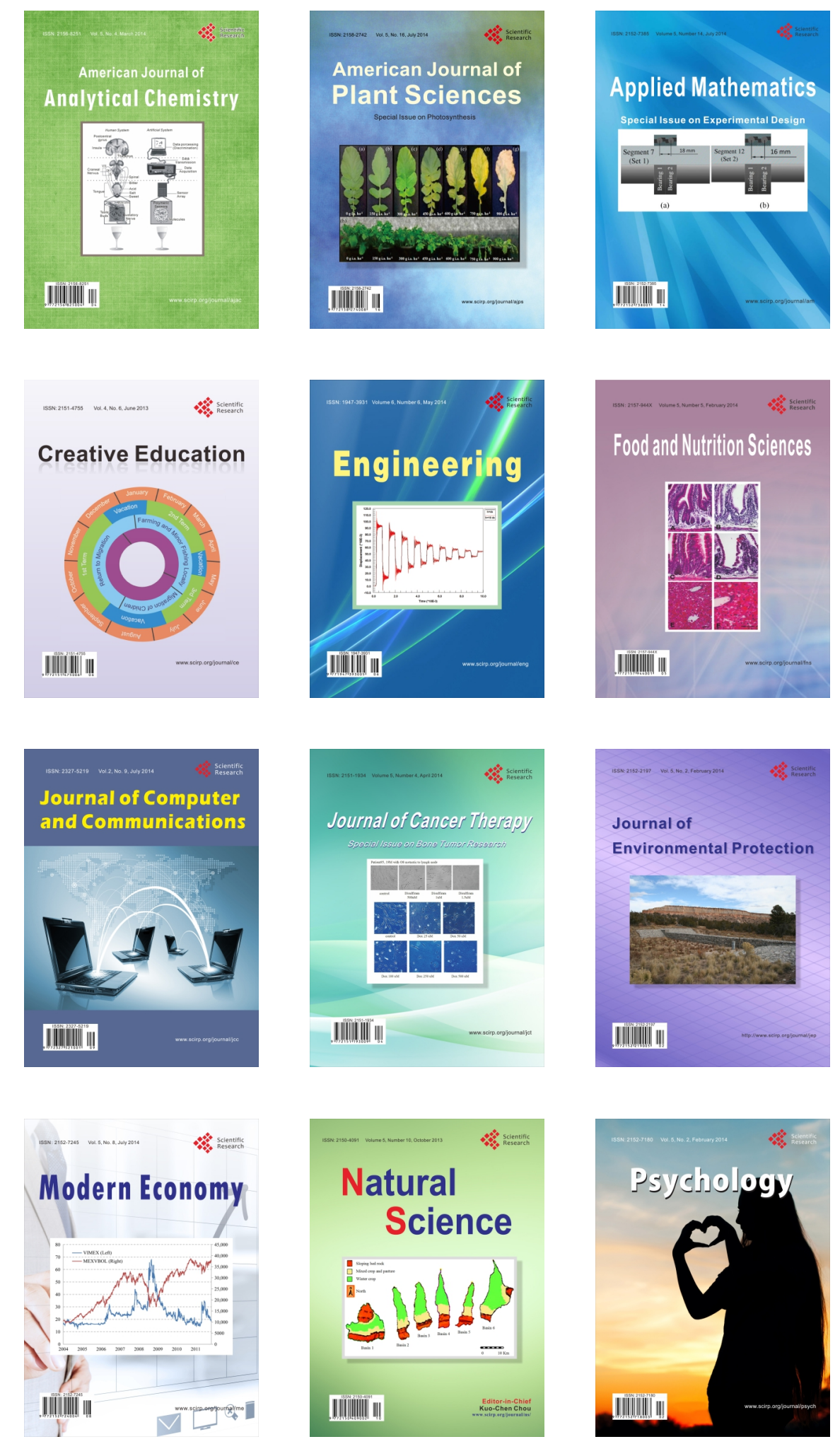